Supplement of Atmos. Chem. Phys., 18, 535-554, 2018

https://doi.org/10.5194/acp-18-535-2018-supplement

(c) Author(s) 2018. This work is distributed under

the Creative Commons Attribution 4.0 License.

(c) (1)

Supplement of

\title{
The impact of nonuniform sampling on stratospheric ozone trends de- rived from occultation instruments
}

\section{Robert P. Damadeo et al.}

Correspondence to: Robert P. Damadeo (robert.damadeo@nasa.gov)

The copyright of individual parts of the supplement might differ from the CC BY 4.0 License. 


\section{Sampling Biases}

The paper details the notion of seasonal sampling biases resulting from non-uniform sampled data being averaged into monthly zonal means. Figures 6 and 7 show a few examples 5 of these potential biases for the three instruments shown in this study. However, the existence of systematically changing sampling biases is more prevalent than can be shown in those few figures. Supplemental figures S1 through S6 give a more extensive look at some of the plots shown in Fig. 6 and ${ }_{10}$ Fig. 7 of the paper.

\section{Different Unit System}

Since the three instruments (i.e., SAGE II, HALOE, and ACE-FTS) do not provide their data in the same unit system, some conversion was necessary. The paper shows results 15 when the regression is performed on data in number density on altitude. However, it is just as reasonable to perform the same analysis when the data is represented in mixing ratio on pressure. Figure $\mathrm{S} 7$ shows the solar cycle response (compare to Fig. 5 of the paper) while Fig. S8 shows the resulting STS ${ }_{20}$ trends (compare to STS trends in Figs. 10 and 11).

\section{Including More Instruments}

The paper details why the occultation instruments with sunsync orbits were omitted for this work. However, this does not mean they could not be included, only that their inclusion ${ }_{25}$ does not add much to the analysis and creates additional complications from limited spatial sampling. Figure $S 9$ shows the correlated and uncorrelated residuals from the six-instrument regression (compare to Fig. 2 of the paper) while Fig. S10 shows the resulting STS trends (compare to STS trends in

${ }_{30}$ Figs. 10 and 11). Note that POAM data is only available between 15 and $50 \mathrm{~km}$. 

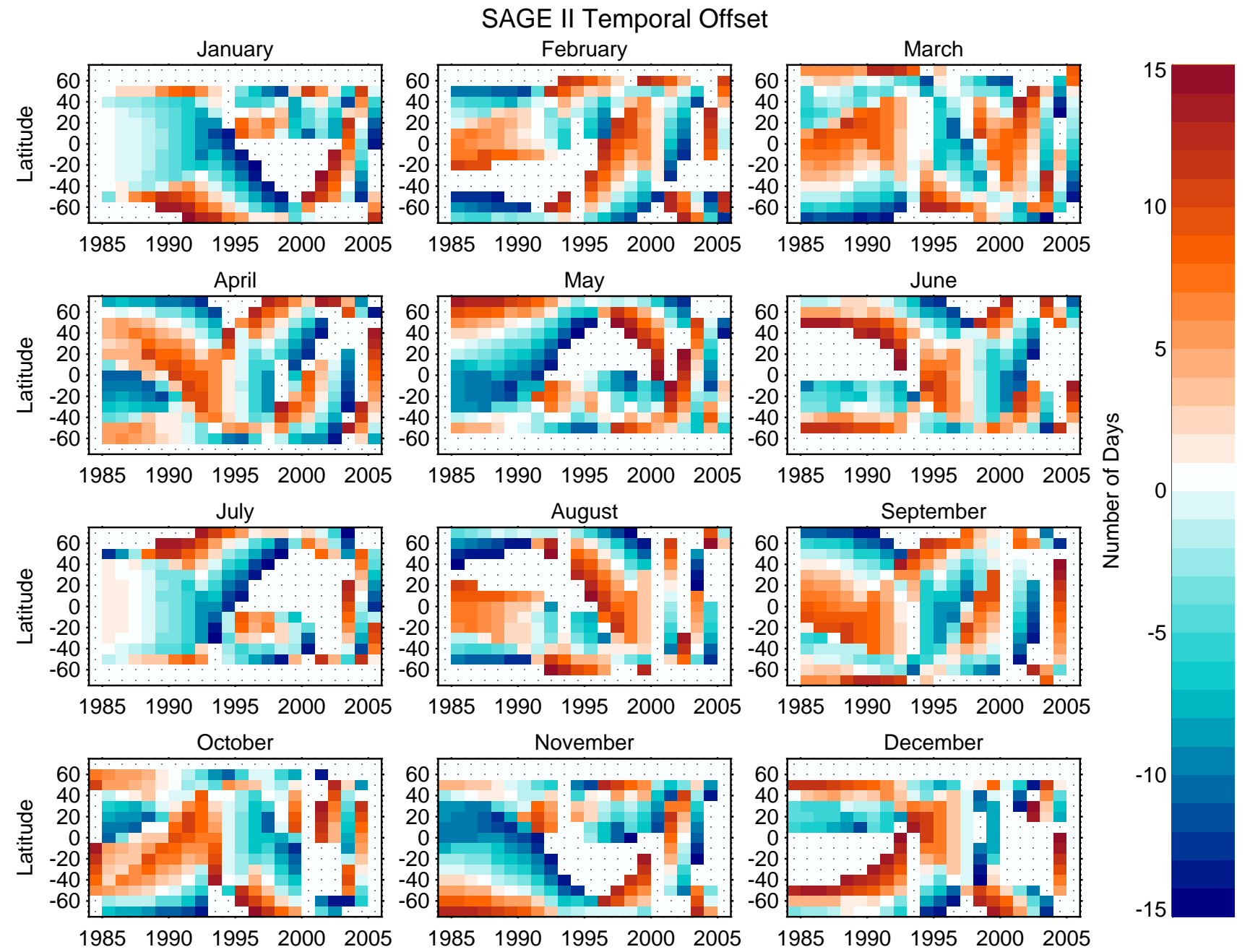

Figure S1. The MZM temporal sampling bias as shown in the top row of Fig. 6 of the paper but for each month of the SAGE II data set. 

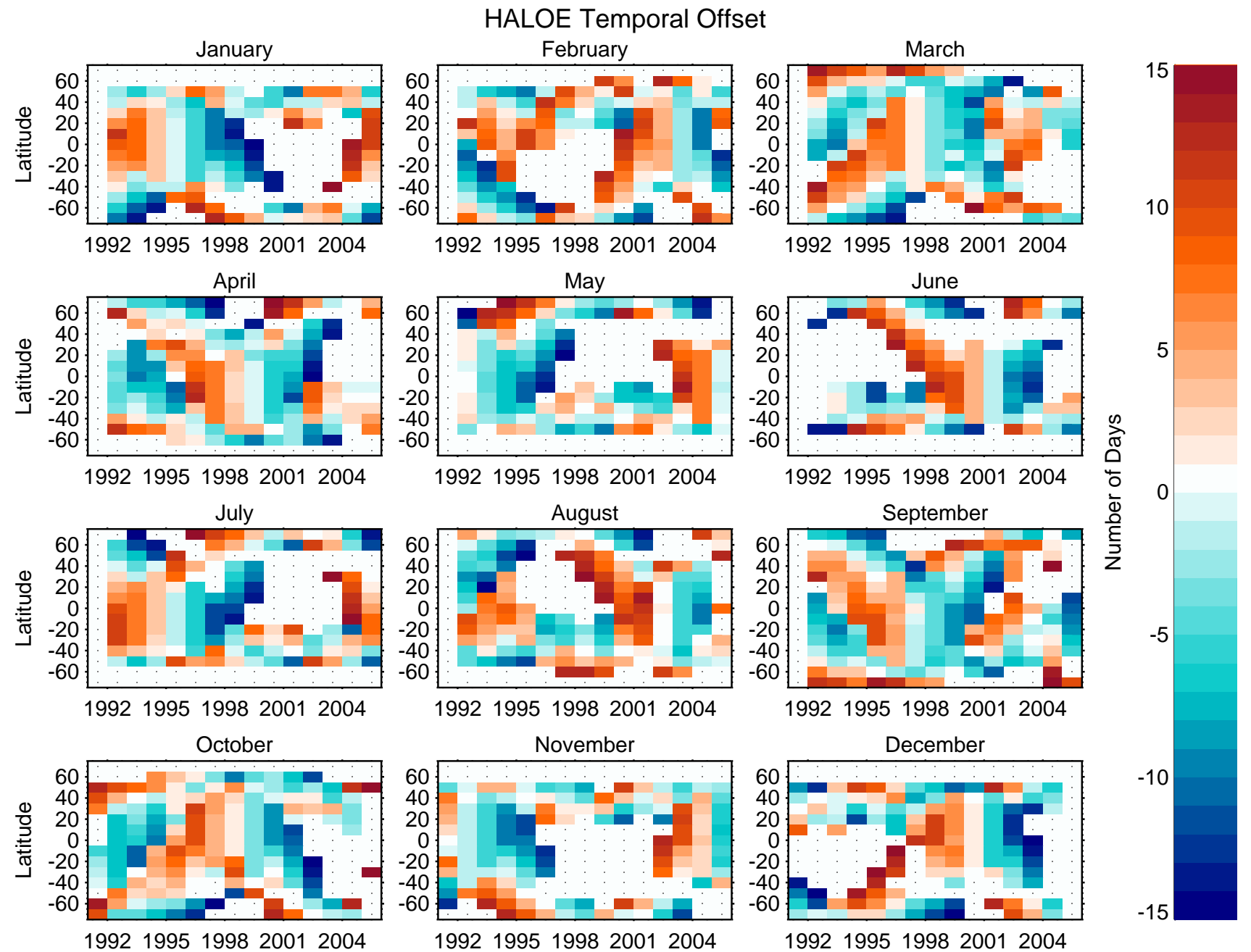

Figure S2. Same as Fig. S1 except for the HALOE data set. 

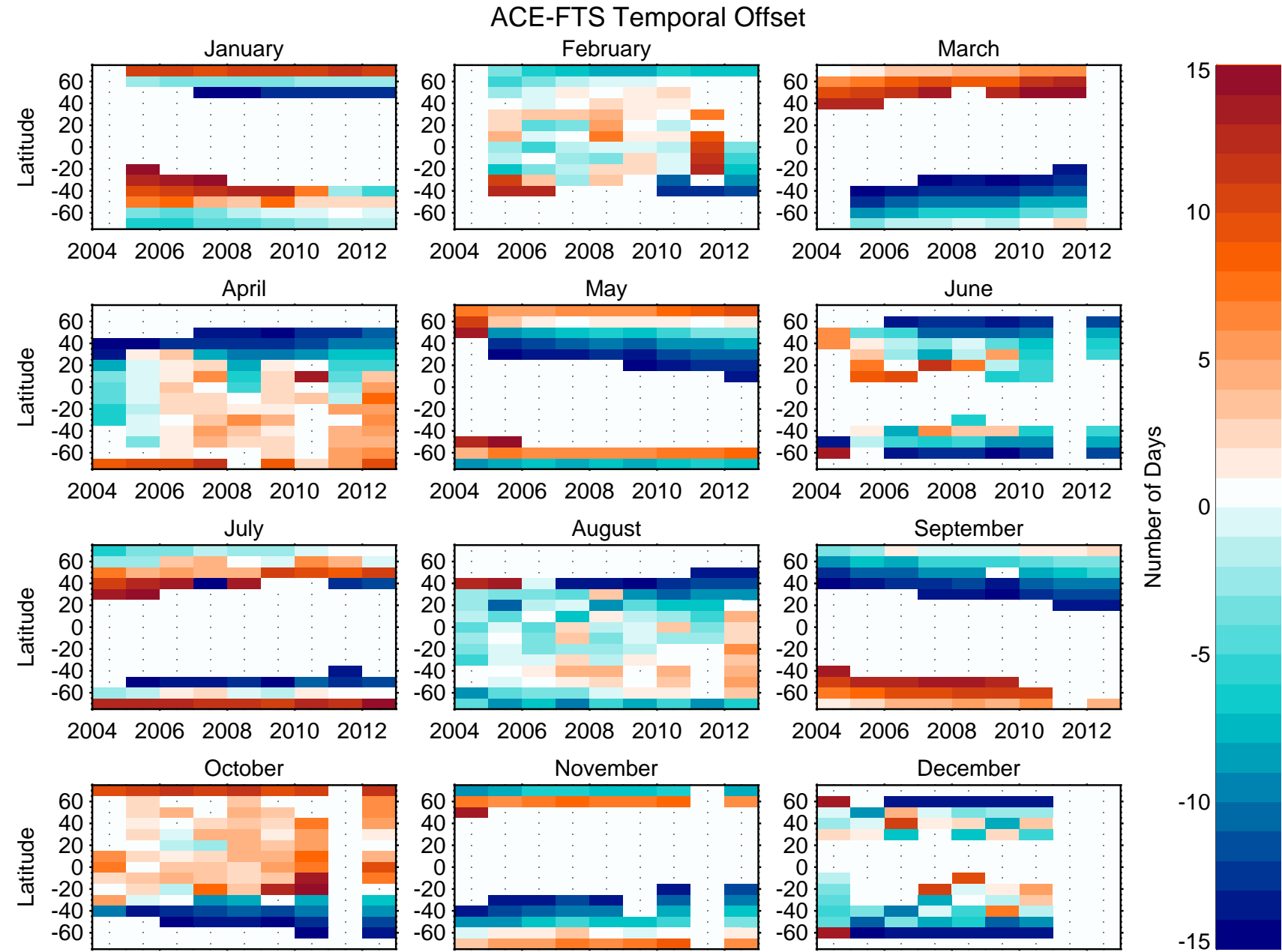

20042006200820102012
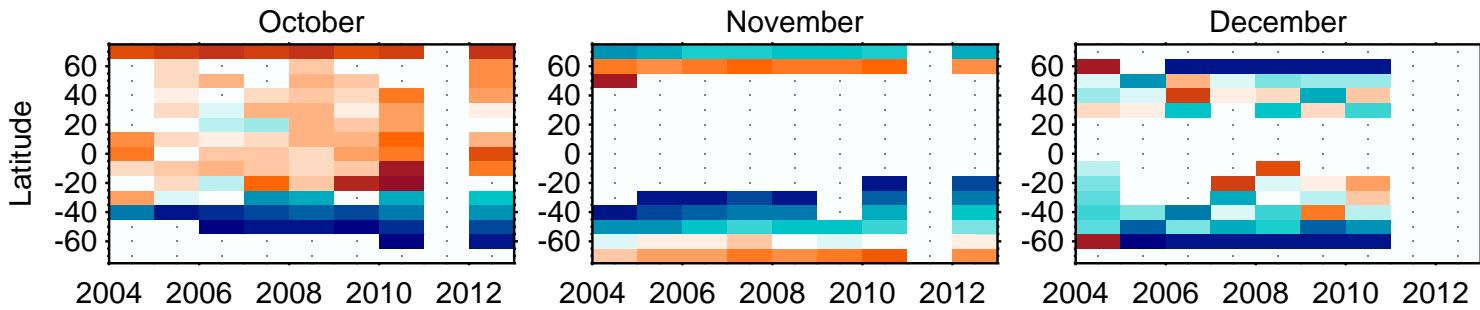

$-15$

Figure S3. Same as Fig. S1 except for the ACE-FTS data set. 


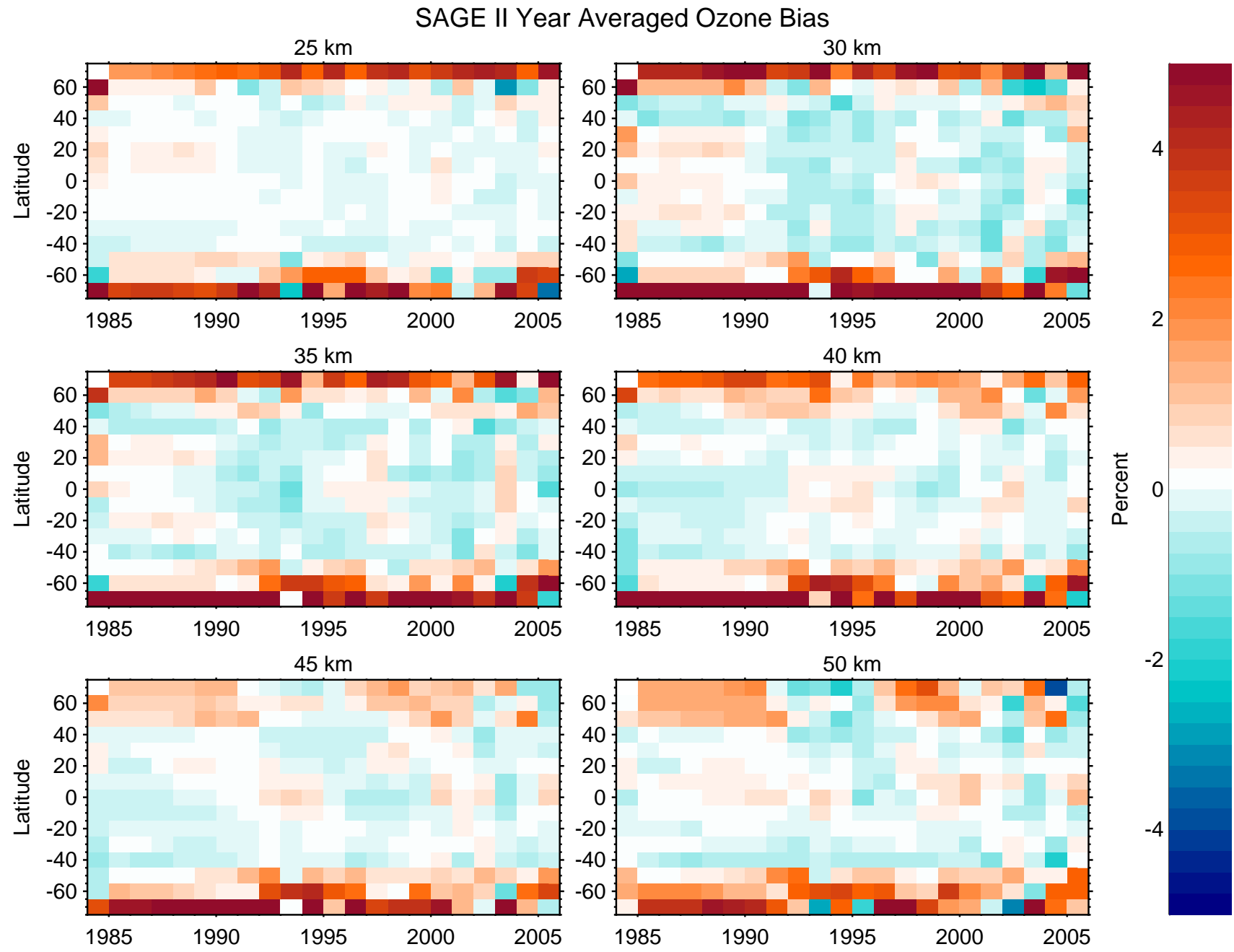

Figure S4. The yearly average of the MZM seasonal sampling biases as shown in the top row of Fig. 7 of the paper but for six different altitudes of the SAGE II data set. 


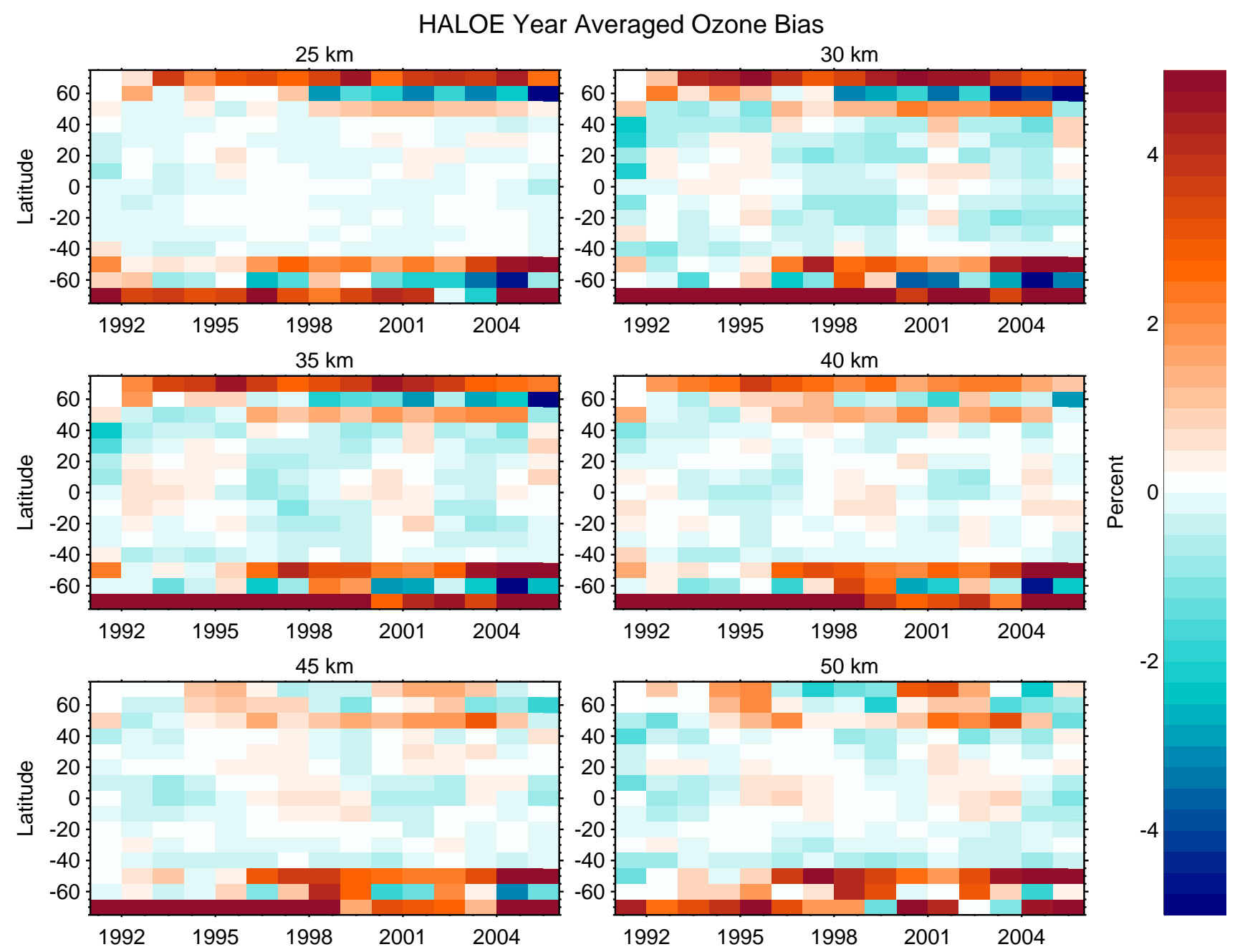

Figure S5. Same as Fig. S4 except for the HALOE data set. 


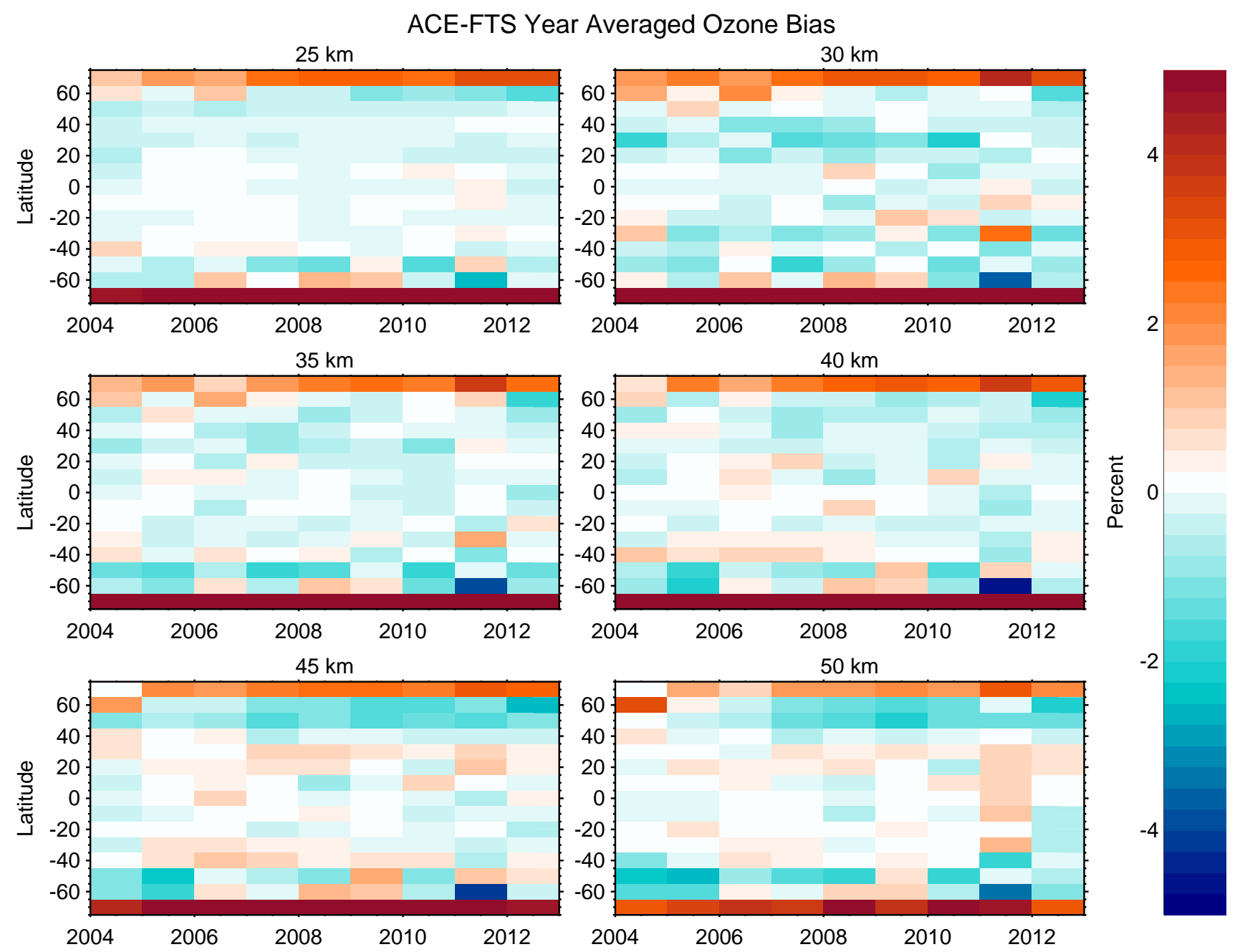

Figure S6. Same as Fig. S4 except for the ACE-FTS data set. 


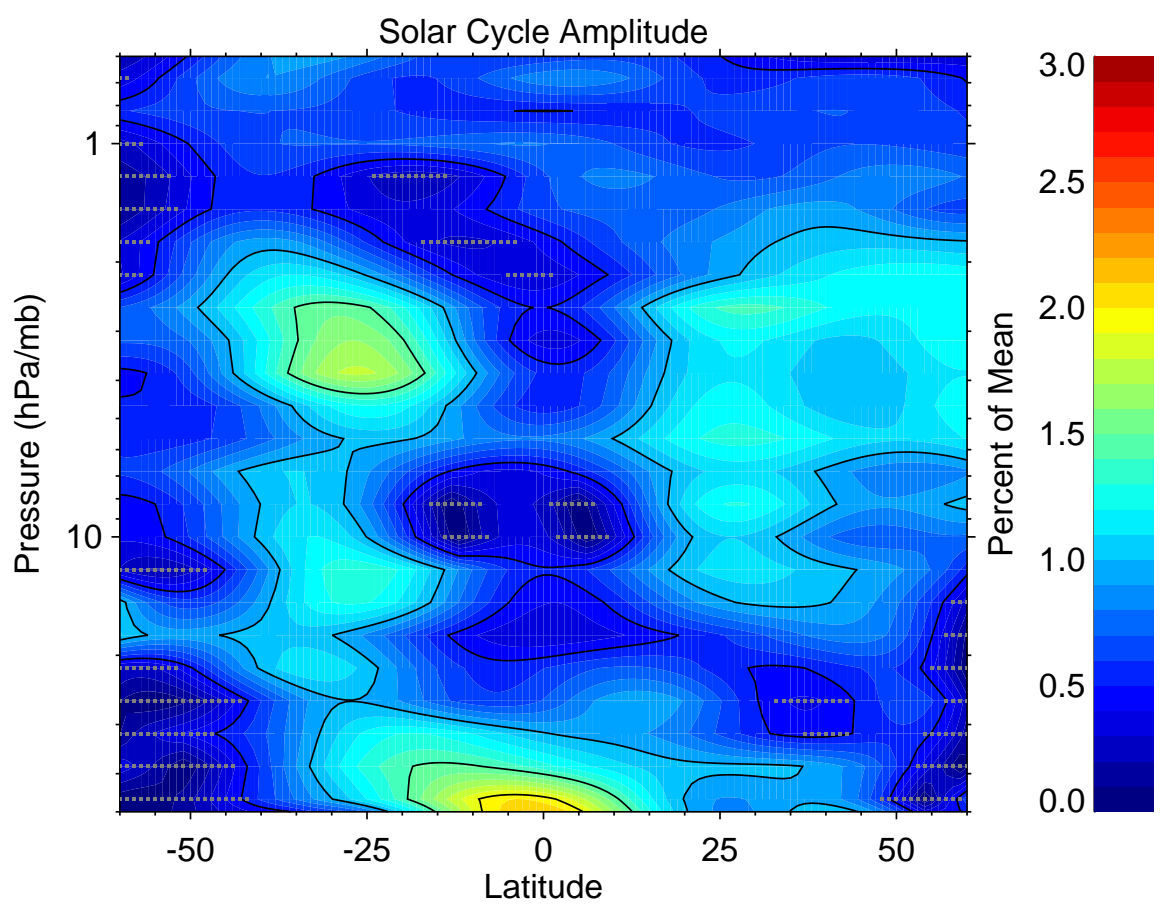

Figure S7. Amplitude of oscillation of the solar cycle response as a percentage of the local mean when the regression is performed for data in mixing ratio on pressure using SAGE II, HALOE, and ACE-FTS data. Stippling denotes areas where the values are not significant at the $2 \sigma$ level. Contour lines are plotted at intervals of $0.5 \%$. 

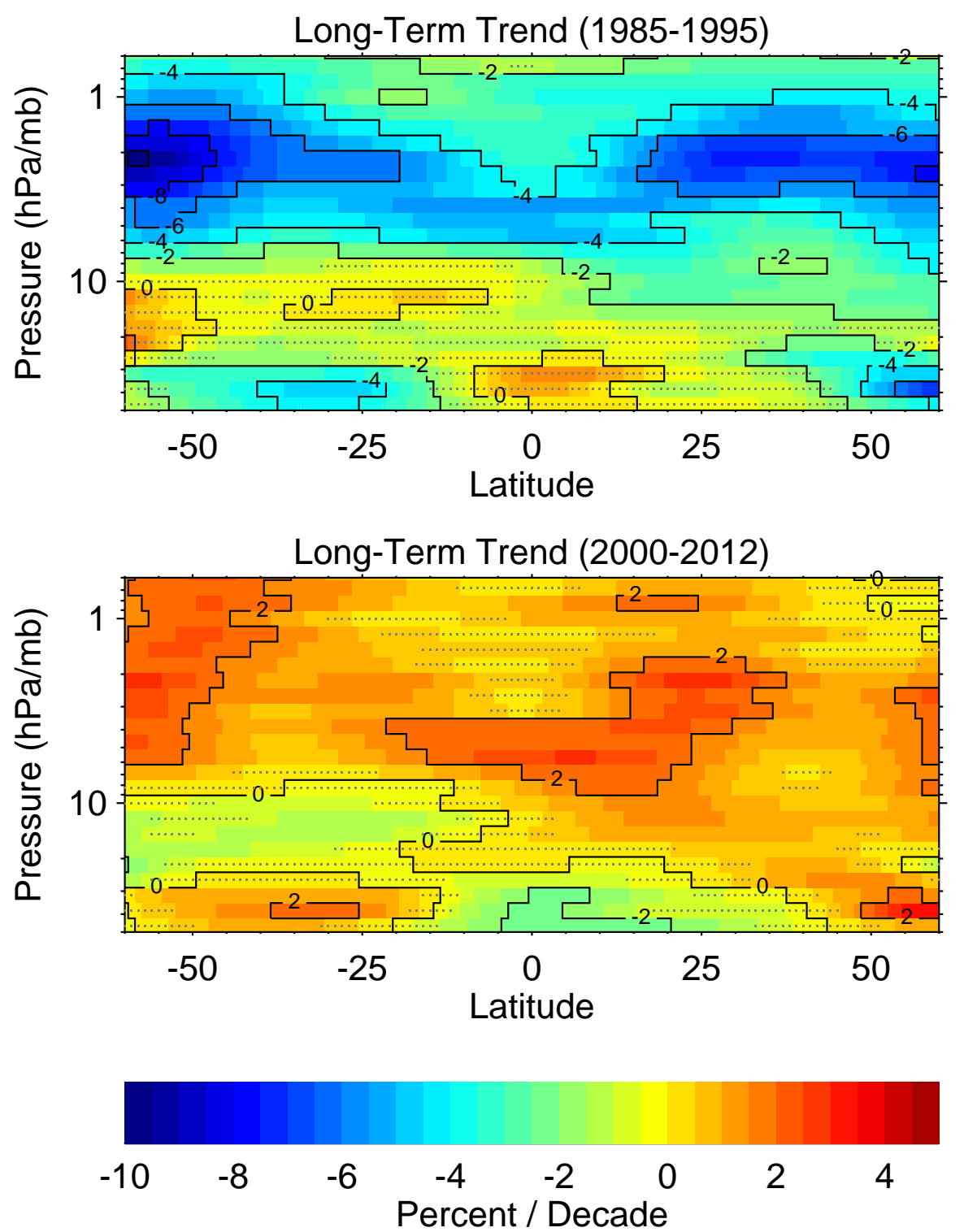

Figure S8. Long-term trends derived from the STS regression on data in mixing ratio on pressure during both the typical decline and potential recovery periods. Stippling denotes areas where the trend results are not significant at the $2 \sigma$ level. Contour lines are plotted at $2 \%$ intervals. 

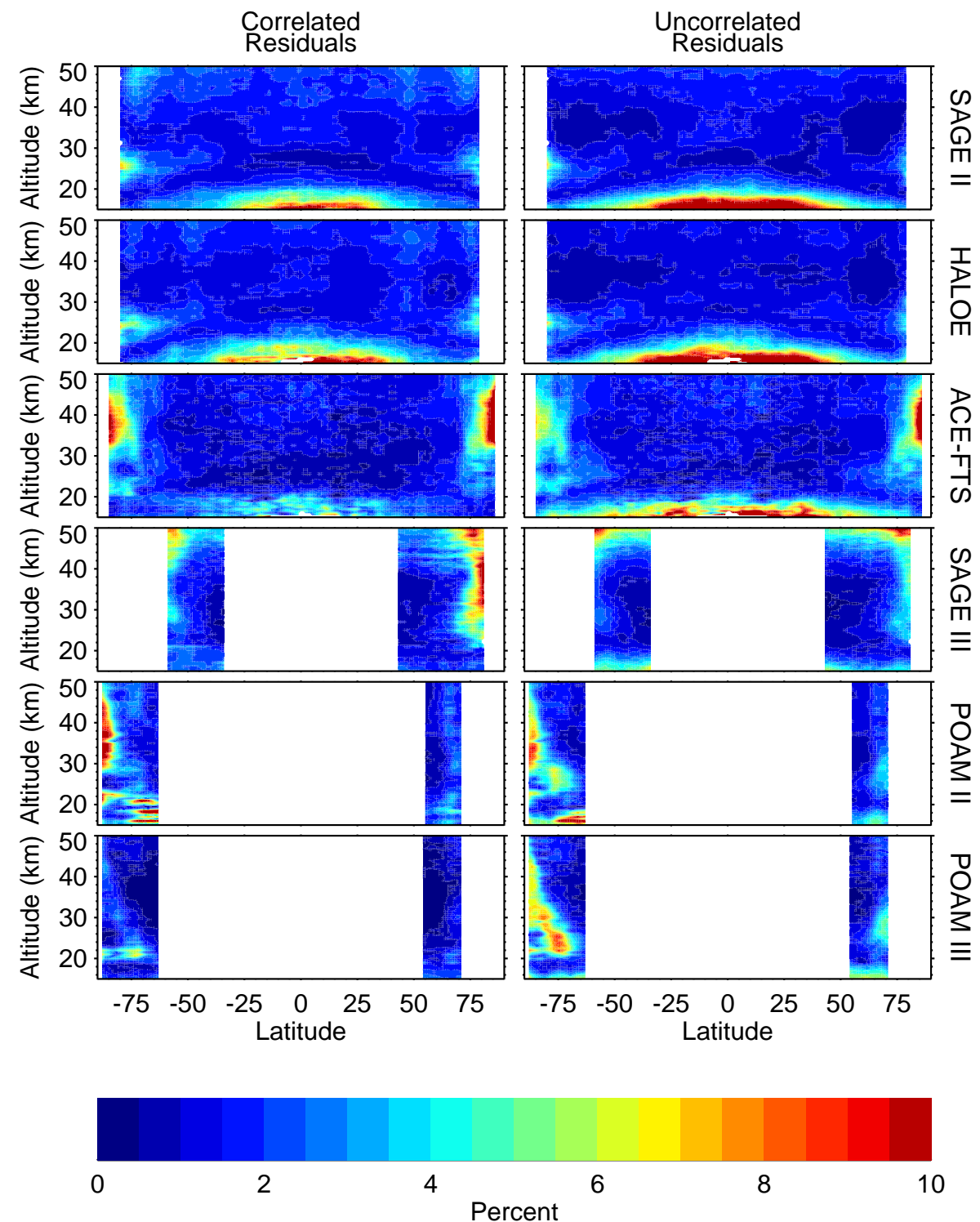

Figure S9. Spread of the correlated and uncorrelated residuals as a function of latitude and altitude for each instrument from the regression when all six occultation data sets are used. White regions show areas where insufficient data exists. 

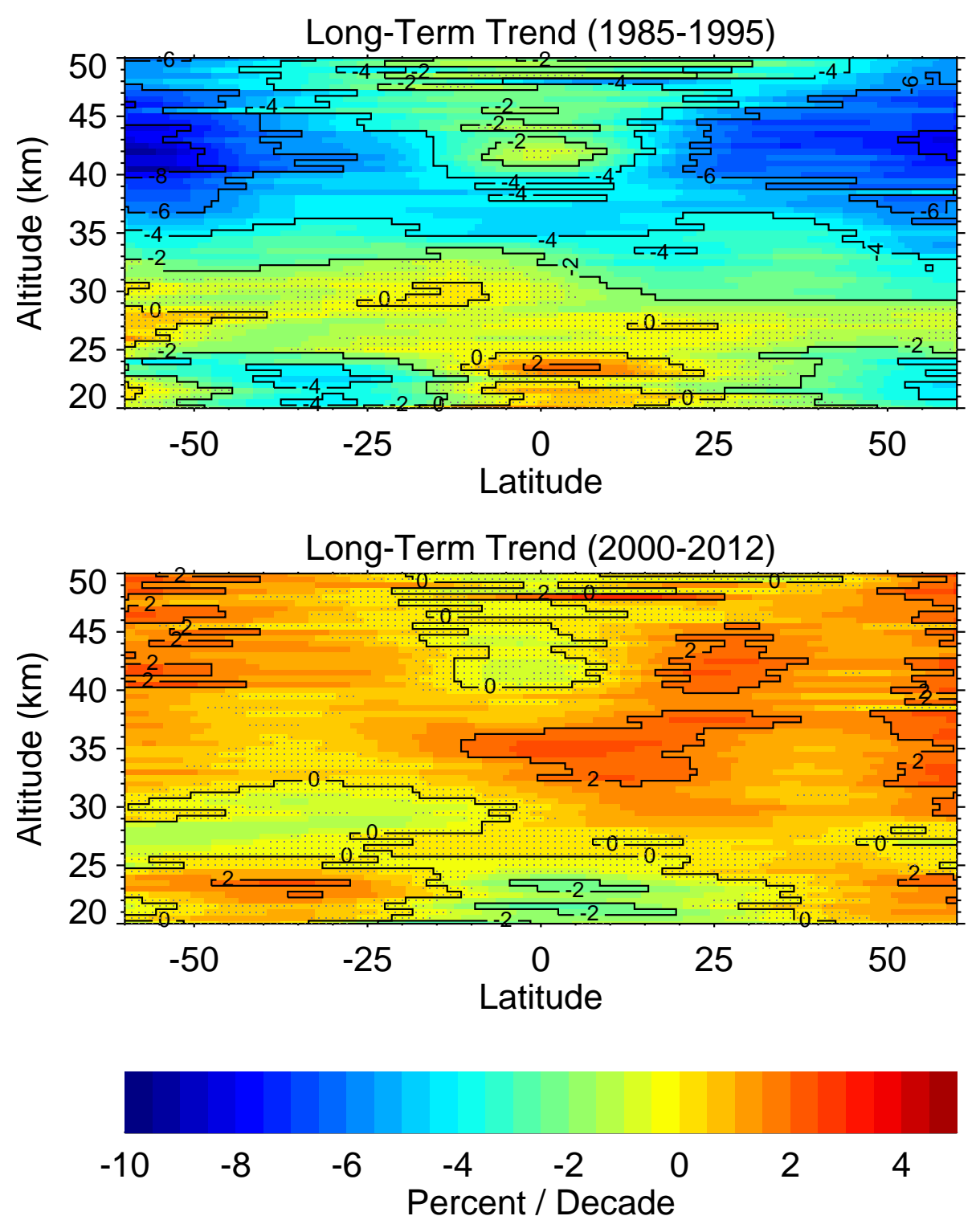

Figure S10. Long-term trends derived from the STS regression when all six occultation data sets are used during both the typical decline and potential recovery periods. Stippling denotes areas where the trend results are not significant at the $2 \sigma$ level. Contour lines are plotted at $2 \%$ intervals. 